\title{
Pulp Mill Effluent Treatment Using Plasma Obtained by High Voltage Electrolysis
}

\author{
Alexsandro A. Matias, ${ }^{a}$ César Reis, ${ }^{a}$ Efraim L. Reis, ${ }^{a}$ Cláudio M. Silva, ${ }^{b}$ \\ Odilaine I. C. Damasceno ${ }^{c}$ and Antônio A. Neves* $*$ \\ ${ }^{a}$ Departamento de Química, Universidade Federal de Viçosa, 36570-900 Viçosa-MG, Brazil \\ ${ }^{b}$ Departamento de Engenharia Florestal, Universidade Federal de Viçosa, 36570-900 Viçosa-MG, Brazil \\ ${ }^{c}$ Colégio de Aplicação, Universidade Federal de Viçosa, 36570-900 Viçosa-MG, Brazil
}

\begin{abstract}
Effluents from pulp mills have a high organic load and can still contain high organic biorecalcitrant material that is harmful to the aquatic environment, even after undergoing biological treatment in effluent treatment plants. This study presents a novel treatment method tested on effluents (prior to and after biotreatment) from a Brazilian kraft pulp mill, based on hydroxyl radical production and hydrogen peroxide obtained by plasma generated by high-voltage electrolysis. These species present significant oxidation potential that could enable the complete breakdown of the organic matter. From the application of plasma to treat pulp mill effluent for a 7-hour period, it was obtained a chemical oxygen demand (COD) removal between 88.2 and $99.7 \%$, total organic carbon (TOC) removal of 90.3 to $95.6 \%$, and a color removal of 95.0 to $98.0 \%$. The final $\mathrm{pH}$ of the treated effluent was 11.6 to 11.9 . The results obtained in this study showed that the high-tension plasma treatment, applied on effluent from kraft pulp mills before and after biological treatment, can be an attractive alternative.
\end{abstract}

Keywords: effluent, pulp industry, electric plasma, high voltage

\section{Introduction}

The pollution of water bodies by industrial effluent discharges is a problem in various regions around the world. Industrial effluent from bleached kraft pulp mills is a potential polluter. It is produced in large quantities during industrial process and can still present significant pollution risks even after primary and secondary biological treatment. In the 1990's, average water use in North American pulp mills was $60 \mathrm{~m}^{3}$ per ton of dry pulp (adt) produced. ${ }^{1}$ Modern mills reduced the specific water consumption to approximately $25 \mathrm{~m}^{3}$ adt $^{-1} .^{2}$ Given this, a mill that produces 5000 adt day $^{-1}$ would consume a water volume of $125,000 \mathrm{~m}^{3}$ day $^{-1}$, equivalent to the water consumption of a city with one million people.

Effluents are rich in organic matter coming from wood (chemical oxygen demand (COD) $>1200 \mathrm{mg} \mathrm{L}^{-1}$ and 5-day biochemical oxygen demand (BOD5) $>350 \mathrm{mg} \mathrm{L}^{-1}$ ) and the effluent treatment plant is normally composed of primary treatment (sedimentation) for suspended solids removal followed by an aerobic biological treatment system, an

*e-mail: aneves@ufv.br activated sludge process being the most commomly used. However, this treatment sequence is not sufficient to remove recalcitrant organics or color. ${ }^{3}$

Therefore, there is a need to look for new treatment options that can be combined with the already existing ones or even replace these, to obtain a final effluent less harmful to the environment. An innovative treatment for this effluent could be the use of plasma obtained through high tension and low current electrolysis.

Plasma is produced via potential difference between two electrodes immersed in an aqueous solution, with plasma formation at the anode, where chemical reactions occur under non-faradaic effects, producing, in addition to the hydroxyl radical $(\mathrm{HO} \bullet)$, various other types of reactive

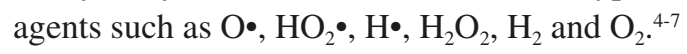

The formation of some of these reactive agents is shown in equations 1 to 5 :

$$
\begin{aligned}
& \mathrm{H}_{2} \mathrm{O} \rightarrow \mathrm{OH} \bullet+\mathrm{H} \bullet \\
& \mathrm{H} \bullet+\mathrm{H} \bullet \rightarrow \mathrm{H}_{2} \\
& \bullet \mathrm{OH}+\bullet \mathrm{OH}_{2} \rightarrow \mathrm{H}_{2} \mathrm{O}_{2} \\
& \bullet \mathrm{OH}+\mathrm{H}_{2} \mathrm{O}_{2} \rightarrow \mathrm{HO}_{2} \bullet+\mathrm{H}_{2} \mathrm{O} \\
& \bullet \mathrm{OH}+\mathrm{HO}_{2} \bullet \rightarrow \mathrm{H}_{2} \mathrm{O}+\mathrm{O}_{2}
\end{aligned}
$$


The use of plasma to breakdown diverse organic compounds has been reported in the literature, amongst these, alquilbenzenosulfonate, which obtained a $90 \%$ mineralization of these compounds. ${ }^{8}$ Regarding monochlorophenol compounds, the results showed a $100 \%$ breakdown within four hours applying plasma. ${ }^{9}$

For the breakdown of dyes, in addition to the use of plasma, studies also investigated the addition of $\mathrm{Fe}^{2+}$ to the solution, as a catalyzing agent for breakdown, which showed more efficient and faster results. ${ }^{10,11}$ Wang et $a l .{ }^{12}$ reports the use of plasma in the treatment of various wastewater, for example, degradation of dyes used in the textile dyeing industry.

The main purpose of the present study was to evaluate the use of plasma obtained by high voltage electrolysis to treat kraft pulp mill effluents.

\section{Experimental}

\section{Effluent sampling and preservation}

The effluents were collected in a Brazilian bleached kraft pulp mill with an ECF (elemental chlorine free) bleaching sequence. The samples were collected before and after the effluent treatment plant, which consisted of an initial clarifier followed by an activated sludge biological process. The effluents were kept under refrigeration $\left(4^{\circ} \mathrm{C}\right)$.

\section{Experimental design}

The system shown in Figure 1 was used, composed of two electrodes to obtain the plasma, a graphite electrode (cathode) and a platinum microelectrode (anode), with a $0.5 \mathrm{~mm}$ diameter and exposure of $2.0 \mathrm{~mm}$ of platinum in contact with the effluent. A thermostatized bath (Frigomix, B Braun Biotech International), a temperature control (Thermomix BM-S, B. Braun Biotech International) for

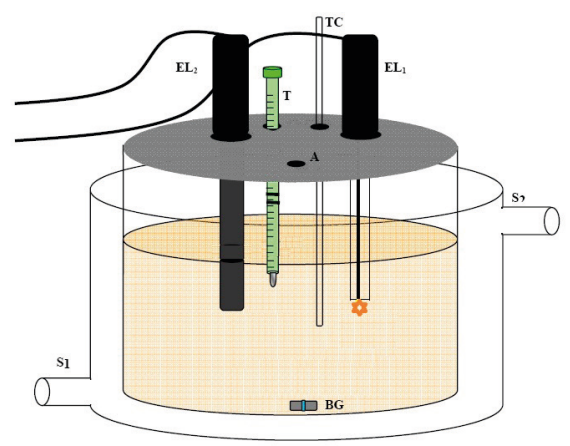

Figure 1. Cell scheme: $\mathrm{EL}_{1}$, platinum electrode; $\mathrm{EL}_{2}$, graphite electrode; A, orifice; TC, capillary tube for sampling; $T$, thermometer; $S_{1}$ and $S_{2}$, in and out flow of water, respectively; BG, magnetic bar. circulation of the refrigeration water and a magnetic stirrer for the homogenization of the reaction medium were used.

The system was used to treat $300 \mathrm{~mL}$ of effluent from a pulp mill, before (EBBT) and after (EABT) biological treatment. A difference in potential of $585 \mathrm{~V}$ and a maximum current of $200 \mathrm{~mA}$ was applied using a high-tension source (DC Power Supply, Supplier). Under constant magnetic stirring, the plasma treatment was maintained during $30 \mathrm{~min}$ to $7 \mathrm{~h}$. This range was chosen because after $7 \mathrm{~h}$ a high COD is generally observed and, therefore, the experiments are stopped. All assays were performed in duplicate.

The physical-chemical characterization of the effluents was performed according to the Standard Methods for the Examination of Water and Wastewater (1998). ${ }^{13}$ The parameters indicated were: COD, total organic carbon (TOC, LAR Process Analysers AG, model Quick TOC), color, chloride $\left(\mathrm{Cl}^{-}\right)$content and $\mathrm{pH}$.

\section{Results and Discussion}

\section{Effluent characterization}

The physical-chemical characteristics of the EBBT and EABT mill effluents are presented in Table 1.

Table 1. Physical-chemical characteristics of the EBBT and EABT mill effluents

\begin{tabular}{lcc}
\hline Parameter & EBBT & EABT \\
\hline $\mathrm{COD} /\left(\mathrm{mg} \mathrm{L}^{-1}\right)$ & $1340 \pm 18$ & $187 \pm 16$ \\
Color / HU $\left(\mathrm{mg} \mathrm{PT} \mathrm{L}^{-1}\right)$ & $207 \pm 19$ & $288 \pm 10$ \\
$\mathrm{pH}$ & $5.18 \pm 0.11$ & $7.95 \pm 0.45$ \\
$\mathrm{TOC} /\left(\mathrm{mg} \mathrm{L}^{-1}\right)$ & $544 \pm 3.5$ & $83 \pm 1.1$ \\
Cloride / $\left(\mathrm{mg} \mathrm{L}^{-1}\right)$ & $275 \pm 10$ & $\mathrm{ND}$ \\
\hline
\end{tabular}

EBBT: effluent before biological treatment; EABT: effluent after biological treatment; COD: chemical oxygen demand; HU: Hazen units; TOC: total organic carbon; ND: not determined.

The COD values for the raw and biotreated effluent are typical for this type of industry. Kamali and Khodaparast ${ }^{3}$ report aCOD range of 1000 to $6000 \mathrm{mgL}^{-1}$ for pulp mill effluent. Color is not affected by primary or secondary biotreatment and, therefore, each pulp mill presents different color values depending especially on their manufacturing process.

\section{Plasma characterization}

For the plasma system used, the following behavior of the current versus voltage (Figure 2) was observed.

Other authors such as Gao et al. ${ }^{11}$ and Gupta ${ }^{14}$ also reported the same behavior for the current versus potential 


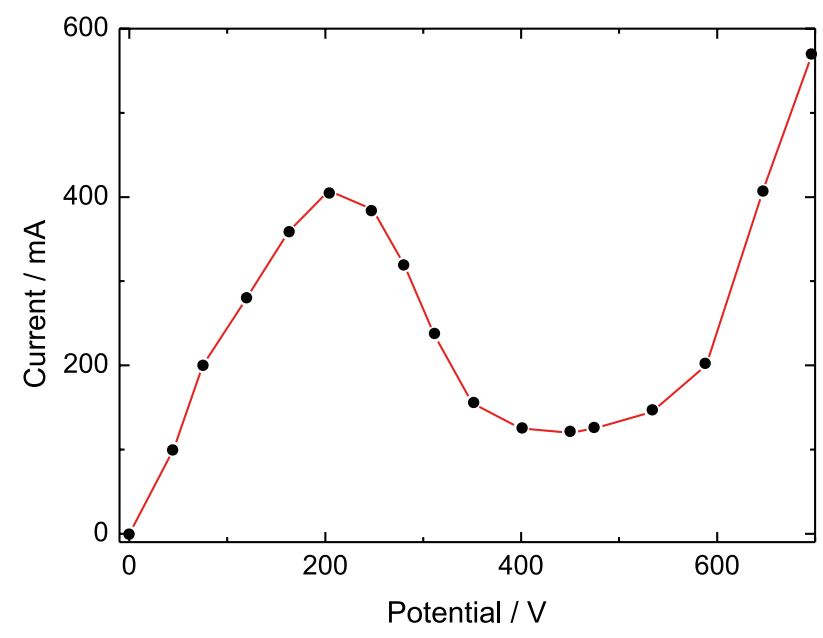

Figure 2. Current curve versus potential difference.

difference. For these authors there is an agreement in terms of the explanation for such behavior.

All authors considered the curve divided into three parts, with the current increasing in the first part, almost proportional to the increase of the applied tension. This suggests that the electrolysis obeys the law of Ohm, with the decomposition of the water and the current being stable during this phase. In the second phase (200-480 V), sparks were observed at irregular intervals and the current became unstable. This can be explained by the large quantity of heat produced near the tip of the anode, making the water around the electrode vaporize. Therefore, the current dropped off abruptly, keeping in mind the electrical resistance of the water vapor. When the tension applied went above $480 \mathrm{~V}$, the current increased once again. This is due to the complete collapse of the water vapor, and the normal electrolysis spontaneously changes to the electrolysis of the luminescent discharge and the plasma formed becomes stable.

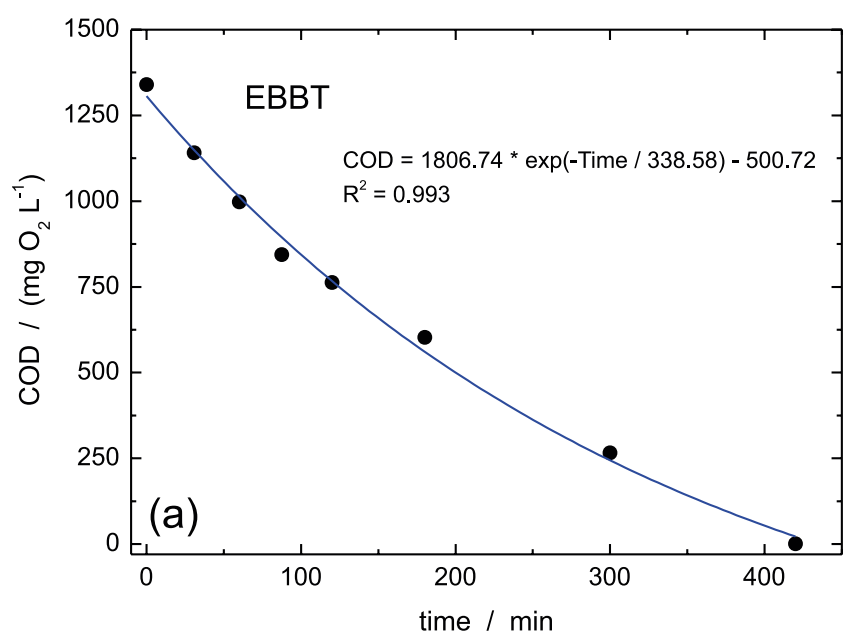

Study of the COD reduction according to time of plasma application in the effluents

The temperature of the thermostatized bath was set at $10{ }^{\circ} \mathrm{C}$. This low value was necessary to dissipate the high heat produced by the plasma, which, according to Gupta, ${ }^{7}$ is a common phenomenum considering the low volume used in a lab-scale experiment $(300 \mathrm{~mL})$. Effluent before (EBBT) and after (EABT) biological treatment and without any correction of $\mathrm{pH}$ was used. Given that the effluent used has a large electrolytic charge sufficient for the formation of the plasma, it was not necessary to add electrolytic support. The response used for the analysis was the COD value. The results are presented in Figure 3.

Based on the graphs presented in Figure 3, an exponential behavior in the breakdown of the effluent organic matter from the pulp mill was observed, finding that within 420 min this value was almost null for the EBBT.

These results show that within a retention time less than the used in the biological treatment for the activated sludge, a more satisfactory result was obtained, considering that in the effluent treated with plasma there was a drastic reduction of organic matter over the time considered.

Study of the TOC reduction with the time of plasma application in the effluent

These analyses were performed to determine the organic carbon content present in the EBBT and EABT effluents, since, contrary to the COD, the analysis of the TOC is independent of the state of oxidation of the organic matter. Additionally, it does not undergo interference from the other atoms connecting with the organic structure such as nitrogen, hydrogen, and inorganic species such as $\mathrm{Fe}^{2+}$, $\mathrm{Mn}^{2+}, \mathrm{S}^{2-}$ and $\mathrm{Cl}^{-}$.

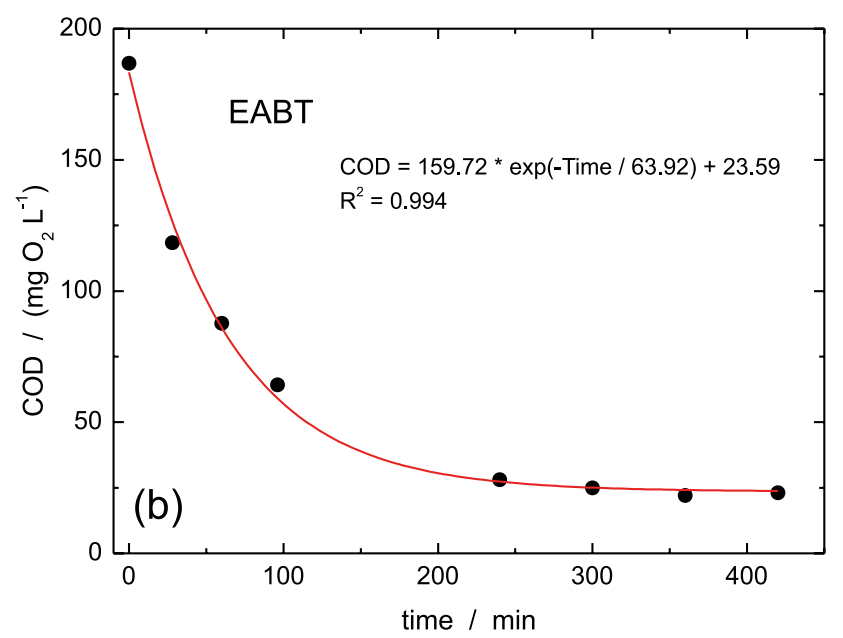

Figure 3. COD values for the effluents from pulp mill (a) EBBT and (b) EABT after the application of plasma, as a function of time. 
The results obtained for the TOC analysis (Figure 4) confirm and show more clearly the exponential behavior of the breakdown of organic matter via plasma treatment, observing that the percentage of TOC removal is between 90 and $96 \%$.

Variation of $\mathrm{pH}$ during the application time of the plasma in effluent

The $\mathrm{pH}$ value is a parameter determined by Brazilian legislation, ${ }^{15}$ and should be between 6.0 and 9.0 to be able to be discharged into the environment. A study of its variability as a function of the application time of the plasma treatment was conducted. The results are presented in Figure 5.

According to the study of the $\mathrm{pH}$, after treatment, the effluent to be discharged required correction to achieve $\mathrm{pH}$ values between 6.0 and 9.0. It is notable that for up to $3 \mathrm{~h}$ of treatment, this correction is facilitated, since the $\mathrm{pH}$ value of the effluent is around 10 .

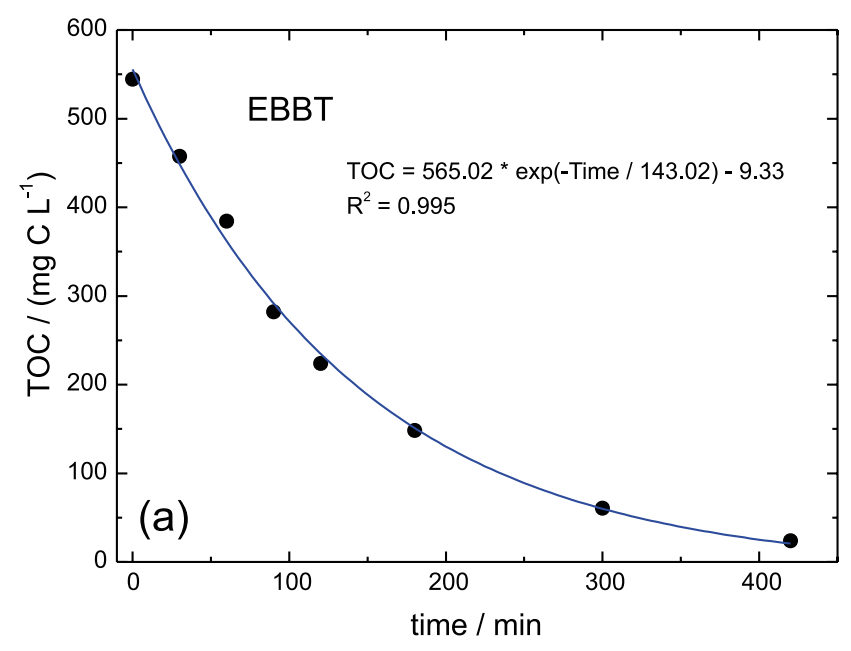

A possible explanation for the increase in $\mathrm{pH}$ can be deduced from the treatment of the effluent, which did not undergo addition of electrolytes. In the electrolysis of water, in the presence of an electrolyte such as sodium sulfate, for example, there is production of $\mathrm{O}_{2}$ in the anode and $\mathrm{H}_{2}$ at the cathode, with the consequent acidification and alkalinization around the electrodes, respectively. Possibly, in the electrolysis under plasma, the phenomena that occur in the platinum microelectrode do not lead to oxidation of the water, but only to oxidation of the organic matter present, in this case, in the effluent. Therefore, there is only alkalization of the medium due to the reduction of water in the cathode.

In the literature, ${ }^{4,12}$ oxidation with plasma presents a decrease in the $\mathrm{pH}$ value. However, in these studies, organic compound solutions prepared in the laboratory were used, in other words, a much less complex matrix than an industrial cellulose effluent.

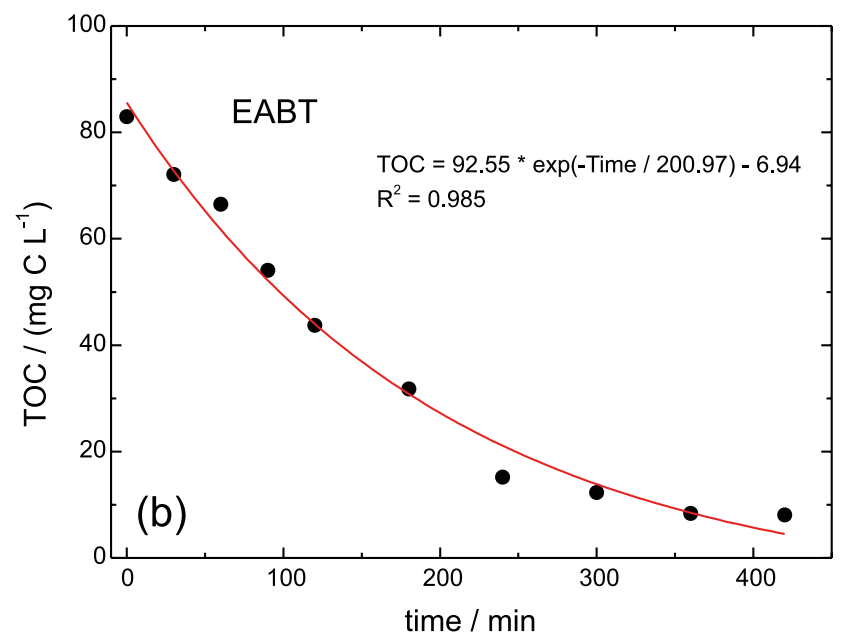

Figure 4. TOC values for the (a) EBBT and (b) EABT after the application of plasma as a function of time.
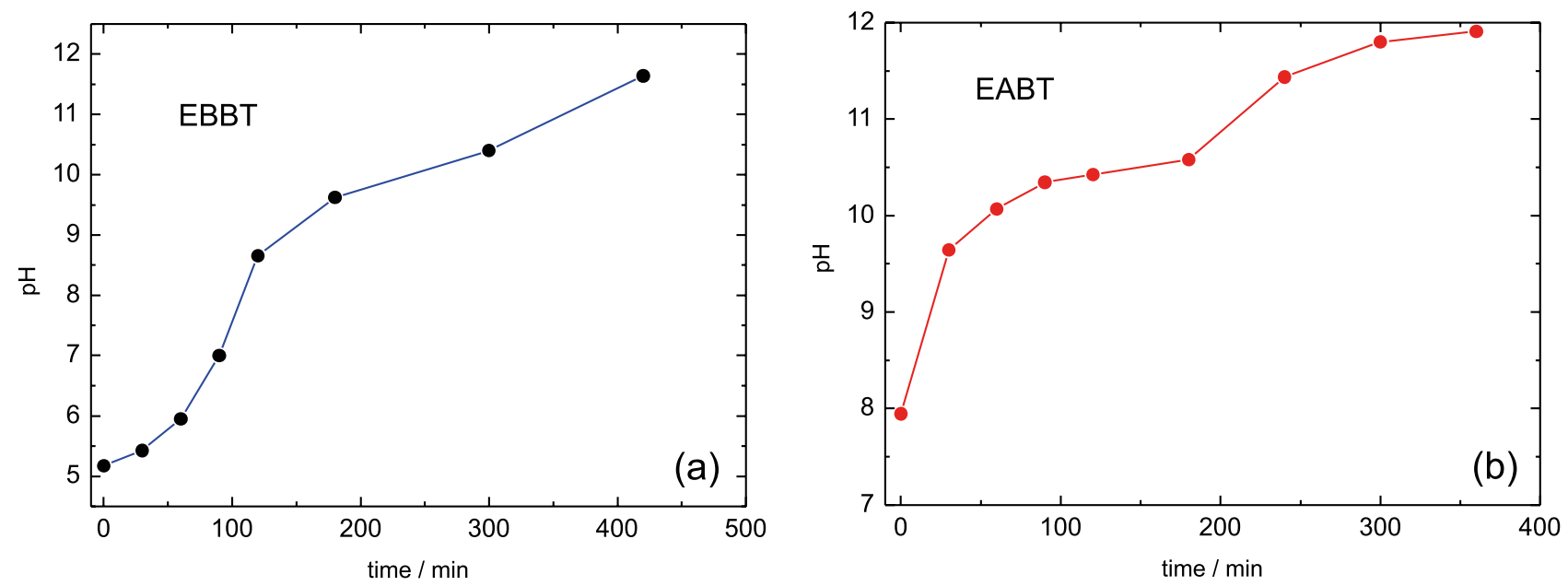

Figure 5. Variation of the $\mathrm{pH}$ for (a) EBBT and (b) EABT after application of plasma as a function of time. 
Study of the color removal from the application of plasma in effluent

Despite color being a parameter without a value defined by Brazilian legislation, which only states that the effluent should not alter the natural color of the receiving water body, ${ }^{15}$ it is an extremely important parameter. In the majority of cases, the persistent color is due to recalcitrant organic compounds that are difficult to breakdown in the receiving water bodies. Figure 6 shows the color values for the different plasma times.

After seven hours of treatment with plasma, nearly $100 \%$ of the color of the EBBT and EABT effluents was eliminated. This result was already expected after the analysis of TOC for these effluents, since over the 7-h period, a value of $23.8 \mathrm{mg} \mathrm{C} \mathrm{L}^{-1}$ was obtained for the EBBT and $8.10 \mathrm{mg} \mathrm{C} \mathrm{L}^{-1}$ for the EABT, which are considered very low values. Given that the most significant agent responsible for the color in these types of effluent is organic

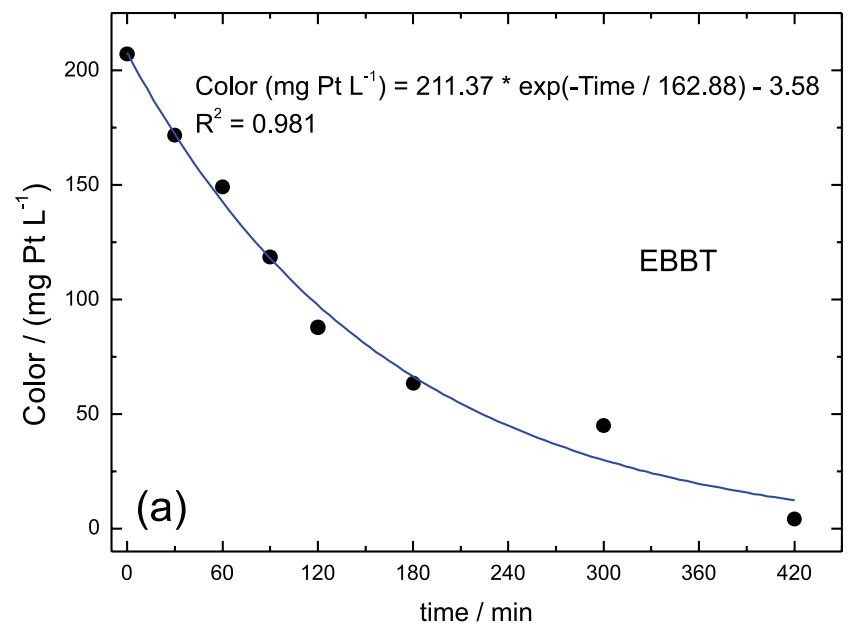

matter, there is an almost total removal of color resultant from its mineralization.

Spectrophotometric analysis of effluent during the plasma application time in effluent

A scan wavelength between 200 to $350 \mathrm{~nm}$ was realized, with close ultraviolet regions, to identify the region with greatest absorbance. In Figure 7, a reduction of absorbance over the whole region studied, during the time of plasma application can clearly be observed, both in the spectra of the effluent before (EBBT) and after (EABT) biological treatment.

In Figure 7, it can be observed that the wavelength of greatest absorption, for the EBBT effluent is around $250 \mathrm{~nm}$, which should be used for analysis. However, to monitor the aromatic compounds derived from lignin, absorbance readings were performed at $280 \mathrm{~nm}^{16}$ to analyze the behavior of the absorbance for different plasma treatment times, as shown in Figure 8.

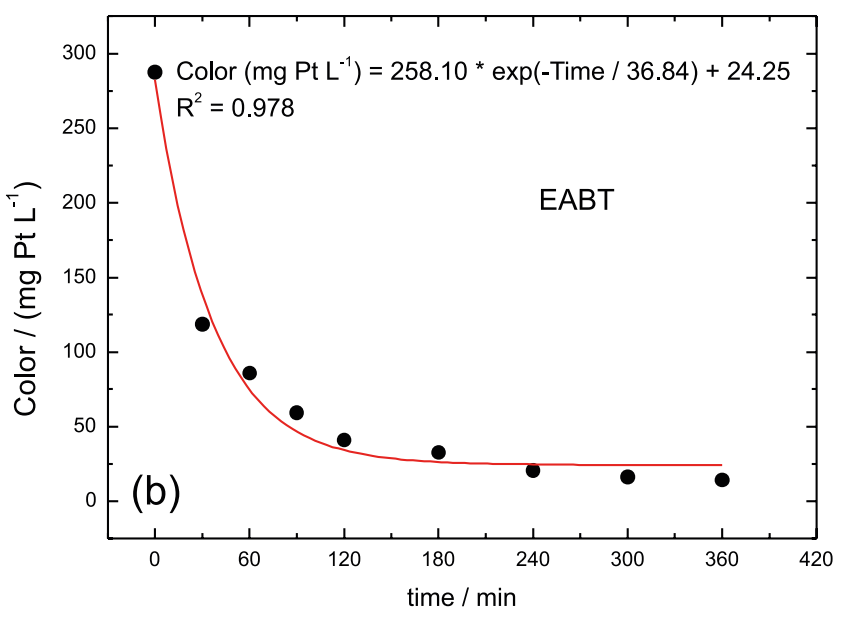

Figure 6. Color values for (a) EBBT and (b) EABT cellulose effluents after the application of plasma as a function of time.
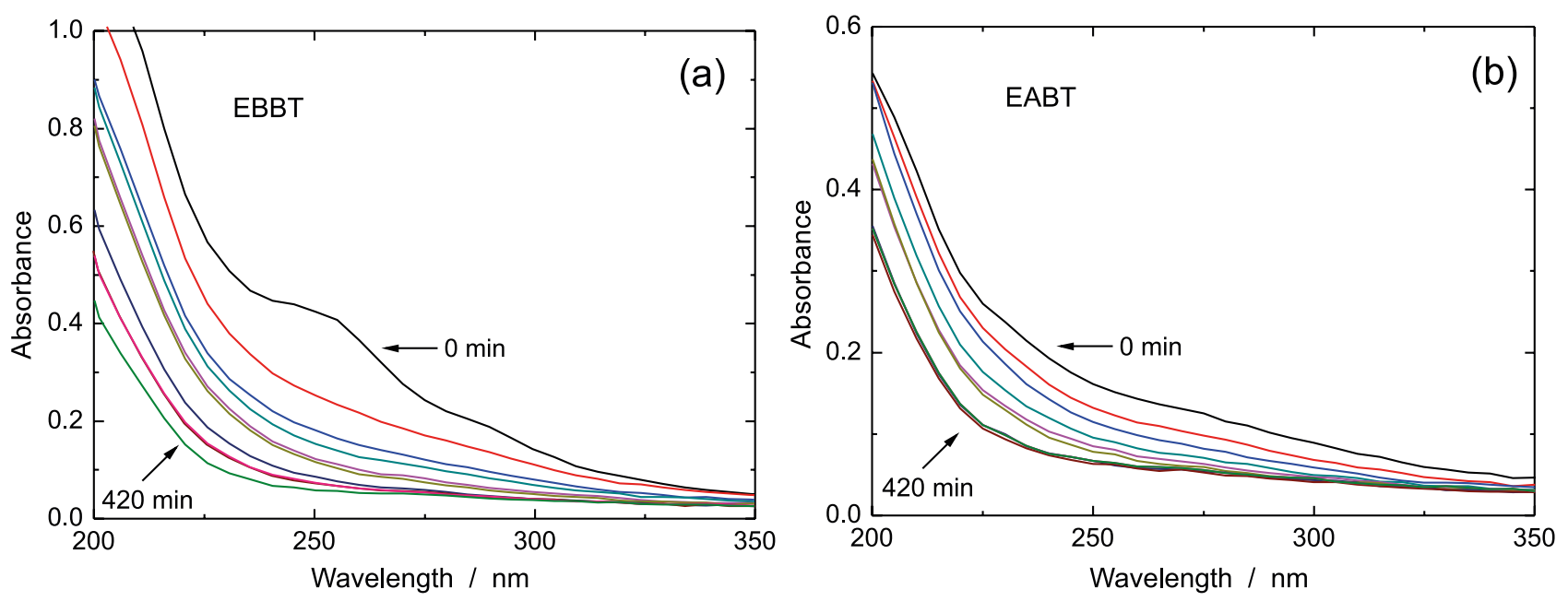

Figure 7. Absorption spectra in the UV-Vis region for the (a) EBBT and (b) EABT cellulose effluents with application of plasma as a function of time. 
Exponential behavior tending toward zero, with an increase in the application time of the plasma was observed. This shows that aromatic compounds, one of the agents responsible for the toxicity of the effluent, are being totally oxidized as shown previously in Figure 4.

\section{Characteristics of EBBT and EABT effluents after the application of plasma}

In addition to the previously mentioned analyses, measurements of chloride concentration in the effluents before and after treatment with plasma were also performed. The results can be found on Table 2 .

From the results obtained, the high $\mathrm{pH}$ value for both EBBT and EABT effluents after treatment with plasma was not in agreement with values cited in the literature. ${ }^{12}$ However, if these effluents were reused during the first bleaching stage, after treatment, the problem of high $\mathrm{pH}$ value would be solved. Therefore, it would be possible to have a closed water cycle system in the kraft pulp mill, which implies in an enormous environmental gain, since the treated effluent of the mill could be used in the bleaching

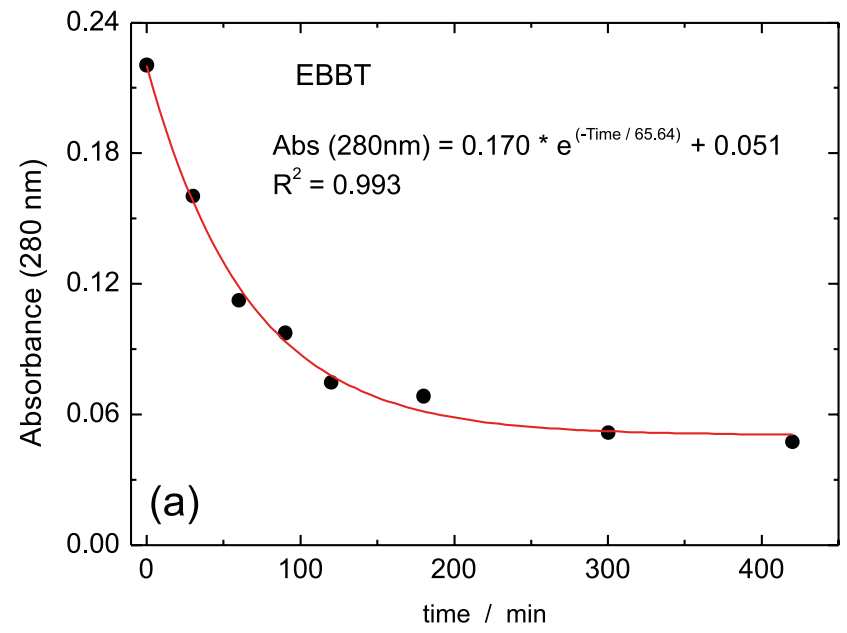

sector. As expected, treatment with plasma did not change the chloride concentration.

Taking into consideration that the treated effluent volume was only $300 \mathrm{~mL}$, even if the electric current was relatively low, the application time of the plasma in the effluent was $7 \mathrm{~h}$, which demands high energy consumption. It is suggested that the plasma treatment be performed in a shorter time span during which the total organic carbon (TOC) would diminish to a manageable level and the rest would be consumed during the biological treatment. Therefore, the energy consumption would be much lower.

\section{Conclusions}

The results obtained in this study showed that the hightension plasma treatment, applied on effluent from kraft pulp mills before and after biological treatment can be an attractive alternative. More than 99\% removal of COD was achieved after seven hours of treatment for EBBT and 88\% for EABT effluents, which is higher than the conventional biotreatment used in pulp mills which is lower than $80 \%$. The activated sludge processes normally used in pulp mills

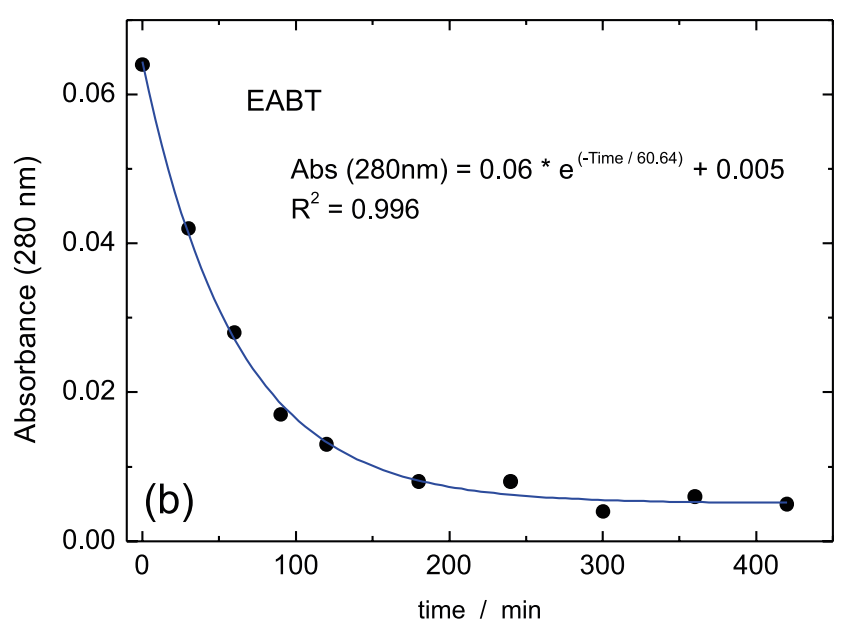

Figure 8. Absorbance at $280 \mathrm{~nm}$ for pulp mill effluent. (a) EBBT; (b) EABT.

Table 2. Results of the physical-chemical characterization of the effluent before (EBBT) and after (EABT) biological treatment and after seven hours of treatment with plasma

\begin{tabular}{|c|c|c|c|c|}
\hline Parameter & EBBT & $\mathrm{EBBT}^{\mathrm{a}}$ & EABT & EABT $^{\mathrm{a}}$ \\
\hline $\mathrm{COD} /\left(\mathrm{mg} \mathrm{L}^{-1}\right)$ & $1340 \pm 18$ & $3.76 \pm 6.10$ & $187 \pm 16$ & $22 \pm 1.30$ \\
\hline Color / HU (mg PT L-1) & $207 \pm 19$ & $4 \pm 0.2$ & $288 \pm 10$ & $14.3 \pm 2.9$ \\
\hline $\mathrm{pH}$ & $5.18 \pm 0.11$ & $11.64 \pm 0.06$ & $7.95 \pm 0.45$ & $11.91 \pm 0.32$ \\
\hline $\mathrm{TOC} /\left(\mathrm{mg} \mathrm{C} \mathrm{L}^{-1}\right)$ & $544 \pm 3.5$ & $23.8 \pm 1.5$ & $83 \pm 1.1$ & $8 \pm 2.1$ \\
\hline Chloride / (mg Cl- $\left.\mathrm{L}^{-1}\right)$ & $275 \pm 10$ & $271.3 \pm 5.7$ & ND & ND \\
\hline
\end{tabular}

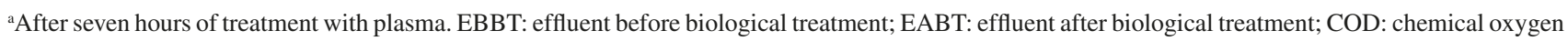
demand; HU: Hazen units; TOC: total organic carbon; ND: not determined. 
have a hydraulic retention time of between 10 to $24 \mathrm{~h}$. This treatment could be an interesting alternative to reduce environmental impacts, considering that it does not require additives, reagents or catalyzers. The process does not produce sludge since all the organic matter is oxidized into $\mathrm{CO}_{2}$. However, there is still a need to improve the energy efficiency of the process that is still considered high for the purpose of water and wastewater treatment.

\section{Acknowledgments}

The authors thank Fundação de Apoio à Pesquisa do Estado de Minas Gerais (FAPEMIG) for MSc scholarship given to the student A. A. Matias and the Conselho Nacional de Desenvolvimento Científico e Tecnológico (CNPq) for financial support.

\section{References}

1. Reeve, D. W.; Silva, C. M. In Chemical Pulping, $1^{\text {st }}$ ed., vol. B; Gullichsen, J.; Fogelholm, C. J., eds.; Fapet Oy: Helsinki, 2000, ch. 22 , p. 441.

2. http://eippcb.jrc.ec.europa.eu/reference/BREF/PP_BREF_ FD_07_2013.pdf, accessed on May 10, 2018.

3. Kamali, M.; Khodaparast, Z.; Ecotoxicol. Environ. Saf. 2015, $114,326$.

4. Lu, Q.; Yu, J.; Gao, J.; J. Hazard. Mater. 2006, 136, 526.
5. Liu, Y.; Wang, D.; Sun, B.; Zhu, X.; J. Hazard. Mater. 2010, 181, 1010.

6. Jin, X.; Wang, X.; Yue, J.; Cai, Y.; Zhang, H.; Electrochim. Acta $\mathbf{2 0 1 0}, 56,925$.

7. Gupta, S. K. S.; Plasma Chem. Plasma Process. 2017, 37, 897.

8. Amano, R.; Tezuka, M.; Water Res. 2006, 40, 1857.

9. Yang, H.; Matsumoto, Y.; Tezuka, M.; J. Environ. Sci. 2009, 21, S142.

10. Gao, J.; Wang, X.; Hu, Z.; Deng, H.; Hou, J.; Lu, X.; Kan, J.; Water Res. 2003, 37, 267.

11. Gao, J.; Li, Y.; Yang, W.; Bo, L.; Yu, J.; Pu, L.; Plasma Sci. Technol. 2006, 8, 198.

12. Wang, X.; Zhou, M.; Jin, X.; Electrochim. Acta 2012, 83, 501.

13. Standard Methods for the Examination of Water and Wastewater, $20^{\text {th }}$ ed.; APHA, Washington, 1998.

14. Gupta, S. K. S.; Plasma Sources Sci. Technol. 2015, 24, 063001.

15. Conselho Nacional do Meio Ambiente (CONAMA); Resolução No. 357, de 17 de março de 2005, Dispõe sobre a Classificação dos Corpos de Água e Diretrizes Ambientais para o seu Enquadramento, bem como Estabelece as Condições e Padrões de Lançamento de Efluentes, e Dá Outras Providências; DOU: Brasília, Brasil, 2005, No. 053, p. 58-63. Available at http:// www.mma.gov.br/port/conama/legiabre.cfm?codlegi=459, accessed in March 2018.

16. Barros, M. J.; Nozaki, J.; Quim. Nova 2002, 25, 736.

Submitted: February 15, 2018 Published online: July 10, 2018 